Military Technical College

Kobry Elkobbah,

Cairo, Egypt

May 25-27,2010

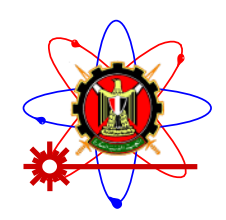

$5^{\text {th }}$ International Conference on Mathematics and Engineering Physics (ICMEP-5)

\title{
PH-26
}

\section{Theoretical and Simulation Studies on Treatment of Breast Cancer using Laser-Induced Photothermal}

\author{
Ashraf F. El-Sherif ${ }^{1}$, Tamer M. kashif
}

\begin{abstract}
The effects of laser irradiation on are of great interest, as they allow for the optimization of hyperthermia treatment. Thermal effect of laser radiation is now used routinely in surgery to incise, coagulate, or vaporize tissues. The laser irradiation power is converted into heat in the target volume with resulting coagulative, necrosis, secondary degeneration and atrophy, and tumor shrinkage with minimal damage to surrounding structures [1].

Accordingly, the main purpose of this study is to develop a finite element model to simulate the laser distribution through the tumor tissue and the heat transfer due to this laser irradiation. Also, we studied the effects of varying laser intensity and cooling conditions at the breast surface. This can be achieved by using finite element models using COMSOL Multiphysics (FEM lab) software
\end{abstract}

\section{1- Introduction:}

Laser radiation is now used routinely to incise, coagulate, or vaporize tissues. The laser light power is converted into heat in the target volume increasing the temperature of the required area causing hyperthermia, secondary degeneration, or tumor shrinkage with minimal damage to surrounding structures [4]. The use of lasers in surgery introduces some desirable features over normal surgical methods such as increased precision, improved homeostasis, and less tissue manipulation.

The biological effects of laser energy depend on the laser wavelength, laser power, the duration of irradiance, blood perfusion, and both the optical and thermal properties of the tissue involved. Laser-tissue interaction mechanisms may be thermal, photochemical, or mechanical in nature [5]. Photochemical is like Photo Dynamic Therapy (PDT). Photomechanical like the effects induced using pulsed lasers (photo acoustic, photo disruptive). The surgical procedures that involve coagulation or ablation of tissue are thermal. Laser irradiation works best for cancers that are rapidly or actively dividing, and recent research suggests that it enhances radio sensitivity of dividing cells by enhancing oxygenation of the tumor tissues. This oxygenation is thought to be caused by increased blood perfusion coupled with a decreased oxygen consumption rate due to mild hyperthermia [6,7]. However, further investigation on the use of hyperthermia in conjunction with radiotherapy is necessary to study the effects of this technique on normal tissues as well as to quantify the vessels due to the increase in temperature.

The thermal effects of laser energy depend on the laser wavelength, laser power, the duration of irradiance, blood perfusion and both the optical and thermal properties of the tissue 
involved. Hyperthermia (also called thermal therapy or thermotherapy) is a type of cancer thermal treatment in which body tissue is exposed to high temperatures (up to $42-43^{\circ} \mathrm{C}$ ) [6,7]. Hyperthermia is almost always used with other forms of cancer therapy, such as radiation therapy and chemotherapy. Hyperthermia may make some cancer cells more sensitive to radiation or harm other cancer cells that radiation cannot damage [7].

Accordingly, the focus of this study is the development of a mathematical model to simulate the heat transfer that causes hyperthermia due to laser irradiation of tumor cells and the effects of varying laser intensity and cooling conditions at the breast surface. We adopted the following schematics from $\mathrm{He}$ et al. [8] to model the effect of temperature on hyperthermia treatment of breast cancer, in which both optical and thermal effects are based on using the transport theory and its approximations, and the temperature rise can be calculated using the bioheat equation.

\section{2- Geometrical Description of the Breast Tissue Model:}

The breast model is assumed to be a hemispherical in shape with a subcutaneous fat layer and tissue regions. A $10-\mathrm{mm}$ diameter tumor is located $6 \mathrm{~mm}$ beneath the surface with its center on the z-axis .Figure 1(a), shows a schematic diagram of a laser-irradiated breast and the solution domain where the laser beam strikes the tissue from a distance.

For the geometry used in our problem Figure 1(a), a mesh convergence analysis is performed. The geometry that is drawn was meshed with a progressively higher number of elements in order to obtain very accurate results of the partial differential equations solved. Triangular elements were employed with a slight increase in mesh density inside and around the tumor region as shown in Fig (1b). The total number of elements used was 1160 elements.

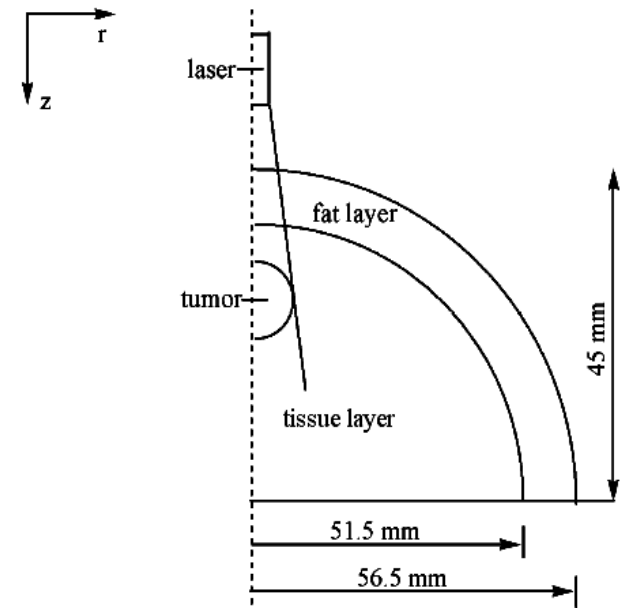

(a)

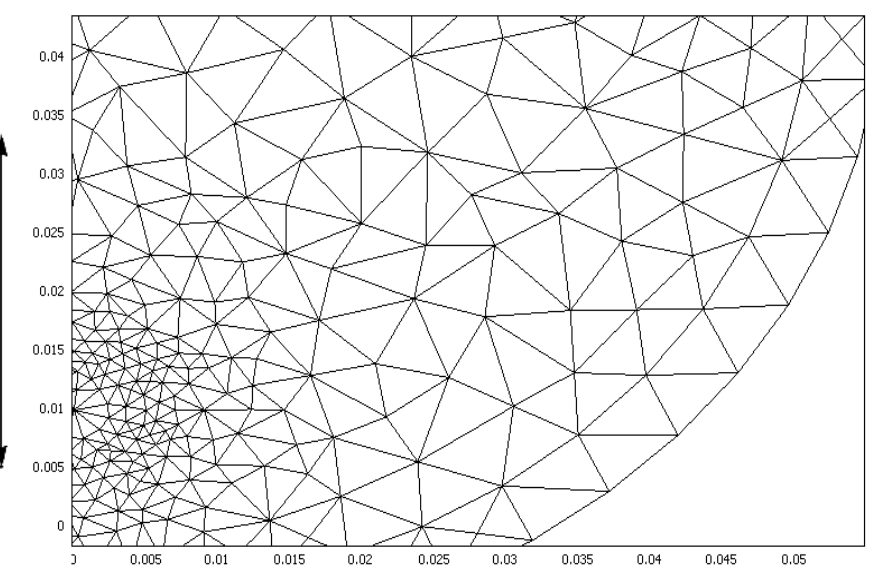

(b)

Fig.1 Breast model (a) Geometrical description schematic of the model (b) Breast model mesh

\section{3- Light Distribution in Tissue:}

In most tissues, both absorption and scattering are present simultaneously. A mathematical description of the absorption and scattering characteristics of light can be performed analytically by using radiative transfer equation (RTE) (some times called transport theory) [9]:

$$
\frac{\partial \mathrm{L}(\overrightarrow{\mathrm{r}}, \hat{\mathrm{s}}, \mathrm{t}) / \mathrm{c}}{\partial \mathrm{t}}=-\hat{\mathrm{s}} \cdot \nabla \mathrm{L}(\overrightarrow{\mathrm{r}}, \hat{\mathrm{s}}, \mathrm{t})-\mu_{\mathrm{t}} \mathrm{L}(\overrightarrow{\mathrm{r}}, \hat{\mathrm{s}}, \mathrm{t})+\mu_{\mathrm{s}} \mathrm{L}(\overrightarrow{\mathrm{r}}, \hat{\mathrm{s}}, \mathrm{t})+\mu_{\mathrm{s}} \int_{4 \Pi} \mathrm{L}(\overrightarrow{\mathrm{r}}, \hat{\mathrm{s}}, \mathrm{t}) p\left(\hat{\mathrm{s}}^{\prime} . \hat{\mathrm{s}}\right) \mathrm{d} \Omega^{\prime}+\mathrm{S}(\overrightarrow{\mathrm{r}}, \hat{\mathrm{s}}, \mathrm{t})
$$

Where $\mathrm{L}(\vec{r}, \hat{s}, \mathrm{t})$ is the radiance, $\mathrm{c}$ is the speed of light in the tissue, as determined by the relative refractive index, $p\left(\hat{\mathrm{s}}^{\prime} . \hat{\mathrm{s}}\right)$ is the phase function, representing the probability that light with propagation direction $\hat{s}^{\prime}$ is being scattered into solid angle $d \Omega$ around $\hat{s}$. 
In most cases, the phase function depends only on the angle between the scattered $\hat{s}^{\prime}$ and incident $\hat{s}$ directions. The scattering anisotropy can be expressed as:

$g=\int_{4 \Pi}\left(\hat{\mathrm{s}}^{\prime} \cdot \hat{\mathrm{s}}\right) p\left(\hat{\mathrm{s}}^{\prime} \cdot \hat{\mathrm{s}}\right) \mathrm{d} \Omega$ , and $\mathrm{S}(\overrightarrow{\mathrm{r}}, \hat{\mathrm{s}}, \mathrm{t})$ describes the light source. The vector representation of the diffusion theory reduces to Fick's law [9]:

$$
\vec{J}(\vec{r}, t)=\frac{-\nabla \Phi(\vec{r}, t)}{3\left(\mu_{a}+\mu_{s}^{\prime}\right)}
$$

which defines current density in terms of the gradient of fluence rate where $\vec{J}(\vec{r}, t)$ is the current density (energy flux) in $\mathrm{W} / \mathrm{m}^{2}, \phi$ is the light fluence rate $(\mathrm{W} / \mathrm{mm}), \mu_{\mathrm{a}}$ is the attenuation coefficient $\left(\mathrm{mm}^{-1}\right)$, Substituting Fick's law into the scalar representation of the RTE gives the diffusion equation [9]:

$$
\frac{\partial \Phi(\vec{r}, t)}{c \partial t}+\mu_{a} \Phi(\vec{r}, t)-\nabla \cdot[D \nabla \Phi(\vec{r}, t)]=s(\vec{r}, t)
$$

Where: $D=\frac{1}{\mu_{\text {eff }}}$ is the diffusion coefficient, where $\mu_{\text {eff }}=\sqrt{3 \mu_{\mathrm{a}}\left[\mu_{\mathrm{a}}+(1+\mathrm{g}) \mu_{\mathrm{s}}\right.}, \mu_{\mathrm{s}}$ is the scattering coefficient $\left(\mathrm{mm}^{-1}\right), \mathrm{s}$ is the source term $\left(\mathrm{W} \cdot \mathrm{mm}^{-3}\right), \mathrm{g}$ anisotropy factor incorporating the effects of directionally dependent scattering. The light diffusion approximation to the transport theory, which is implemented in our model can be written as [4]:

$$
D \nabla \phi(r, z)+\mu_{a} \phi(r, z)=s(r, z)
$$

the absorption coefficient $\mu_{\mathrm{a}}$ for visible and for near infrared radiation ranges $0.001 \mathrm{~mm}^{-1}<\mu_{\mathrm{a}}$ $<10 \mathrm{~mm}^{-1}$ for biological tissues, while for the scattering coefficient $\mu_{\mathrm{s}}$ is in the order of $1 \mathrm{~mm}^{-}$ ${ }^{1}<\mu_{\mathrm{s}}<100 \mathrm{~mm}^{-1}$. The optical properties $\mu \mathrm{a}$ and $\mu^{\prime}$ s depend on the tissue, and they change their values during a real treatment [4]

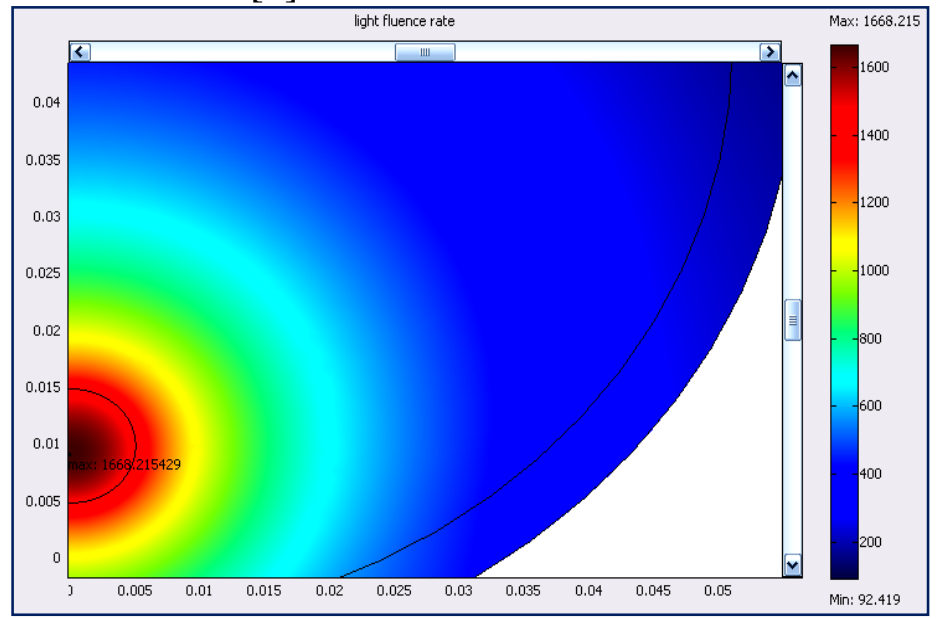

Fig. 2 Shows the solution of light distribution (fluence rate ${ }^{\phi}$ ) in $\mathbf{W} / \mathbf{m}^{2}$

It is shown that the amount of light absorbed by different regions of the tissue depends on optical and thermal parameters of different parts of the tissue including the tumor because of different scattering and absorption coefficients.

\section{4- The Heat Distribution Equation in Tissue:}

The aim of irradiation with laser energy is to produce heat in the targeted tissue. Excess heat is either stored or extracted, leading to changes in the local temperature. The bioheat equation was constantly used to describe the heat changes in biological tissue. The bioheat transfer equation is a parabolic partial differential equation, which is given by [10]: 


$$
\delta_{t s} \rho z \frac{\partial T}{\partial t}+\nabla \cdot(-k \nabla T)=\rho_{b} C_{b} \omega_{b}\left(T_{b}-T\right)+Q_{m e t}+Q_{e x t}
$$

Where $\rho$ is the tissue density $\left(\mathrm{kg} / \mathrm{m}^{3}\right), c$ is the specific heat of tissue $(\mathrm{J} / \mathrm{kg} . \mathrm{K}), k$ is the tissue's thermal conductivity $(\mathrm{W} / \mathrm{m} . \mathrm{K}), \rho_{b}$ is the density of blood $\left(\mathrm{kg} / \mathrm{m}^{3}\right), C_{b}$ is the specific heat of blood $(\mathrm{J} / \mathrm{kg} . \mathrm{K}), \omega_{\mathrm{b}}$ is the blood perfusion rate $\left(\mathrm{sec}^{-1}\right), T_{b}$ is the arterial blood temperature $(\mathrm{K})$, $Q_{m e t}$ is the heat source from metabolism $\left(\mathrm{W} / \mathrm{m}^{3}\right)$, and $Q_{e x t}$ is the spatial heat source $\left(\mathrm{W} / \mathrm{m}^{3}\right)$. The laser power intensity along the tissue depth $\left(Q_{\text {ext }}\right)$ is expressed by Lambert-Beer's law, as [8]:

where $\mathrm{I}_{0}$ is the laser beam intensity

$$
I(r, z)=I_{0}(r) e^{-(\mu a+\mu s) z} .
$$

Heat generation due to scattering is assumed to be negligible; therefore, the specific absorption rate in the target zone can be expressed as follows [8]:

$$
\mathrm{Q}=-\frac{d I}{d Z}=-(\mu \mathrm{a}+\mu \mathrm{s}) \mathrm{I}_{0}(\mathrm{r}) \mathrm{e}^{-(\mu \mathrm{a}+\mu \mathrm{s}) \mathrm{z}}
$$

Since the diameter of the tumor is about $10 \mathrm{~mm}$ then the irradiated diameter is set to be 10 $\mathrm{mm}$. The heat transfer coefficient at the surface of the breast is calculated by a standard heat transfer coefficient for spheres, which is $458 \mathrm{~W} / \mathrm{m}^{2} \mathrm{~K}$ when the temperature of cooling water is $10^{\circ} \mathrm{C}$ and $13.5 \mathrm{~W} / \mathrm{m}^{2} \mathrm{~K}$ when cooling is the ambient air. Table (1) lists the heat transfer coefficient when the breast tissue is cooled by air or by water $[8,11]$.

Table (1) Boundary properties (taken from He et al. [8] and $\mathrm{Ng}[11]$ ):

\begin{tabular}{|l|l|l|l|}
\hline Cooling Method & & $\mathbf{1 0}^{\circ} \mathbf{C}$ Water & Ambient Air \\
\hline Heat Transfer Coefficient $(\mathbf{h})$ & $\mathrm{W} / \mathrm{m}^{2} \mathrm{~K}$ & $458[8]$ & $13.5[11]$ \\
\hline External Temperature $\left(\mathbf{T}_{\text {inf }}\right)$ & $\mathrm{K}$ & 283 & 298 \\
\hline
\end{tabular}

Thermo physical parameters are required for calculating the variation of temperature during heating the breast tissue with laser. Table (2) lists the thermo physical (Sub- domain) properties values used in the analysis.

Table (2) Sub-domain properties (taken from He et al. [8]):

\begin{tabular}{|l|l|l|l|l|l|}
\hline Properties & & FAT & tissue & tumor & blood \\
\hline Density & $\mathrm{Kg} \cdot \mathrm{m}^{-3}$ & 930 & 1050 & 1050 & 1100 \\
\hline Specific Heat & $\mathrm{J} \cdot \mathrm{kg}^{-1} \cdot \mathrm{K}^{-1}$ & 2770 & 3770 & 3770 & 3300 \\
\hline Thermal Conductivity & $\mathrm{W} \cdot \mathrm{m}^{-1} \cdot \mathrm{K}^{-1}$ & 0.22 & 0.48 & 0.48 & 0.45 \\
\hline
\end{tabular}

\section{5- Simulation Results of Temperature Increasing on Breast Model:}

Transient analysis of temperature in the breast during laser treatment gave a temperature surface plot after 900s of heating as shown in Figure (3). The result is appears very similar to that reported by $\mathrm{He}$ et al [8]. As can bee seen in the temperature profile, significantly elevated temperatures are limited to the tumor and only a small portion ( 1-2 $\mathrm{mm})$ of surrounding healthy tissue. Moreover, the relationship between average tumor temperature and time was also very similar to that observed by $\mathrm{He}$ et al [8].

The temperature rises quickly at the start of the procedure, and it reaches a steady-state value at around $42^{\circ} \mathrm{C}$ after roughly $900 \mathrm{~s}$ with laser power fluence of $1.3 \mathrm{~W} / \mathrm{cm}^{2}$ where the temperature profile, significantly elevated temperatures are limited to the tumor and only a small portion ( 1-2 mm) of surrounding healthy tissue. At this stage, the blood perfusion and cooling of the skin surface prevents the temperature from increasing even more. Average tumor temperature during laser heating as a function of time on the tumor boundary is shown in Figure (4). 


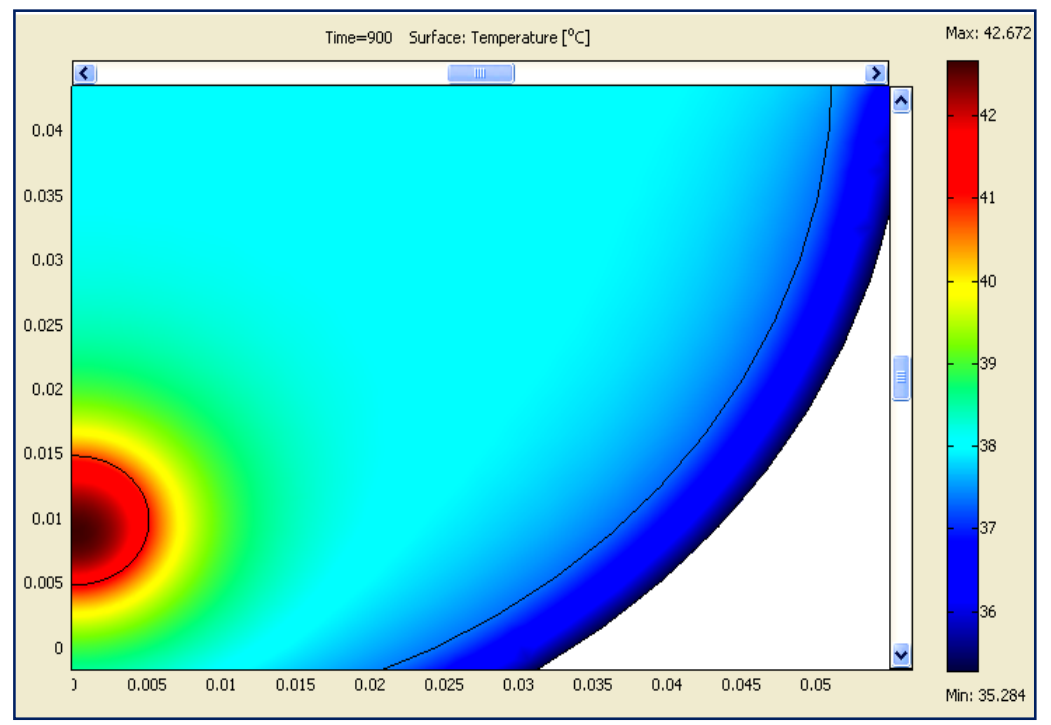

Fig. 3 Show the temperature increase over time at certain point of the tumor.

At the beginning of laser heating the average tumor temperature is $37^{\circ} \mathrm{C}$ as the rest of the breast tissue, then it begins to increase over the time until it reaches near $42^{\circ} \mathrm{C}$ which is the temperature required for the hyperthermia treatment.

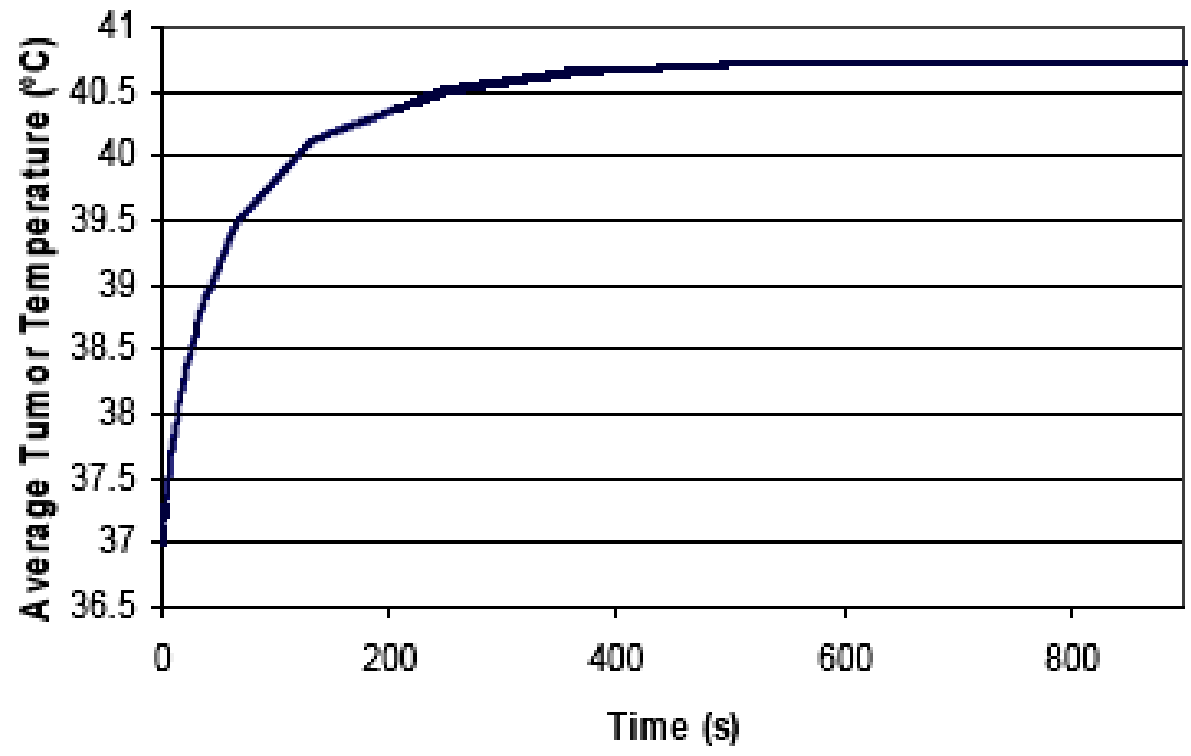

Fig. 4 Average tumor temperatures over time during laser heating 


\section{6- Sensitivity Analysis of the Models:}

\subsection{Cooling at the Breast Surface:}

In order to investigate the importance of the boundary conditions at the breast surface, we examined two scenarios: a cooling flow of $\left(10^{\circ} \mathrm{C}\right)$ water over the breast surface with $h=458$ $\mathrm{W} / \mathrm{m}^{2} \mathrm{k}$ (as used by He et al. [8]) and room temperature $\left(25^{\circ} \mathrm{C}\right)$ air at the breast surface with $h$ $=13.5 \mathrm{~W} / \mathrm{m}^{2} \mathrm{k}$ (as used by $\mathrm{Ng}$ et al. [11]).

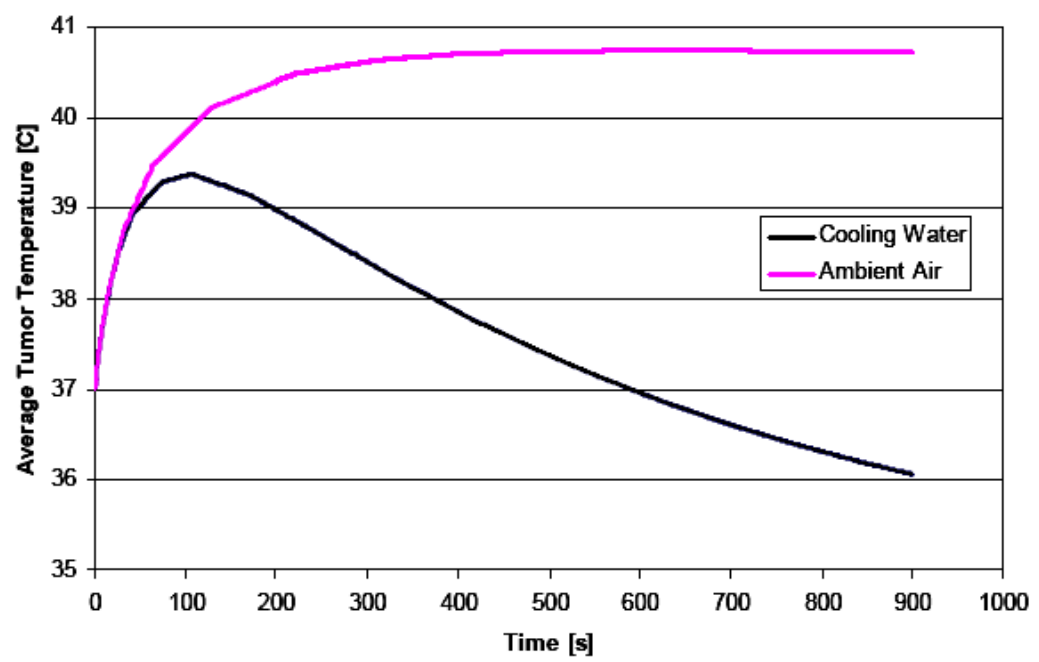

Fig. 5 Average tumor temperature versus time for cooling water (blue line) and ambient air (red line) boundary conditions at the breast surface.

Our results showed that the former condition resulted in an overall cooling of the breast and tumor over time in which the average tumor temperature reduced to nearly of $36^{\circ} \mathrm{C}$, due to the dominating effect of the cooling water, as opposed to the desirable temperature-time plot observed for the air boundary condition (Figure 5).

\subsection{Laser Intensity:}

In order to both examine the sensitivity of our model to laser intensity and determine an optimal laser intensity to be used in hyperthermia treatment of breast tumors, the laser intensity has been varied of $\left(13000 \mathrm{~W} / \mathrm{m}^{2}\right)$ by $+/-20 \%$ to be $10500 \mathrm{~W} / \mathrm{m}^{2}$ and $8000 \mathrm{~W} / \mathrm{m}^{2}$ and $+/-40 \%$ to be $18000 \mathrm{~W} / \mathrm{m}^{2}$ and $15500 \mathrm{~W} / \mathrm{m}^{2}$, then examined the effect on average tumor temperature with time. The results are shown in Figures $(6,7)$.

By increasing the laser intensity to $2500 \mathrm{~W} / \mathrm{m}^{2}$, we have noticed that the temperature increase of $0.7^{\circ} \mathrm{C}(\sim 1.5 \%)$ in the near-steady state average temperature was achieved in the tumor as shown in Figures $(6,7)$.
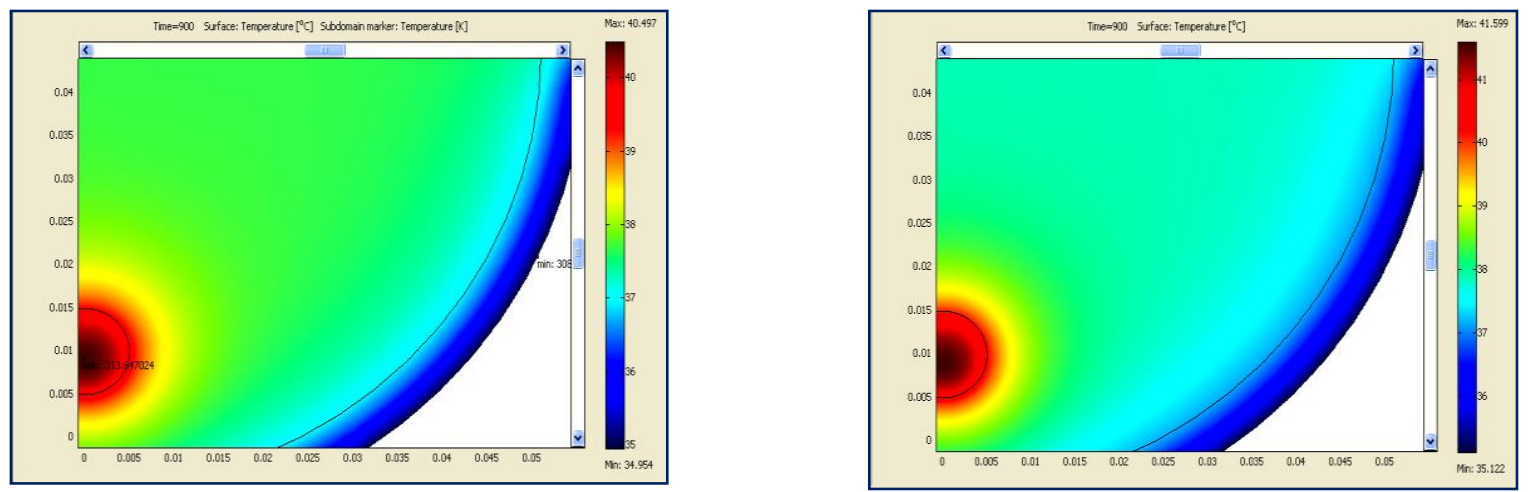
(a)

(c)

(e)
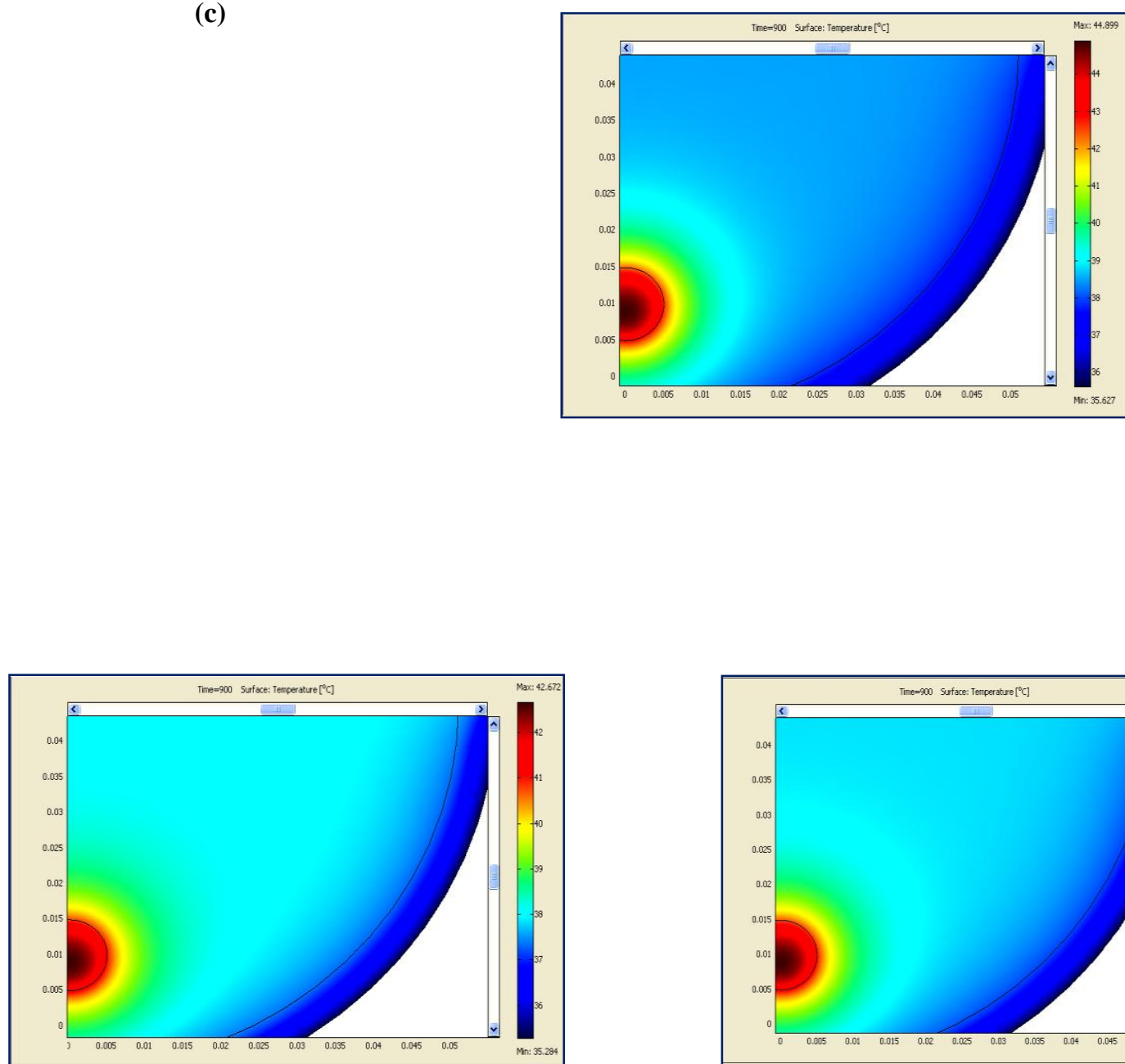

(d)

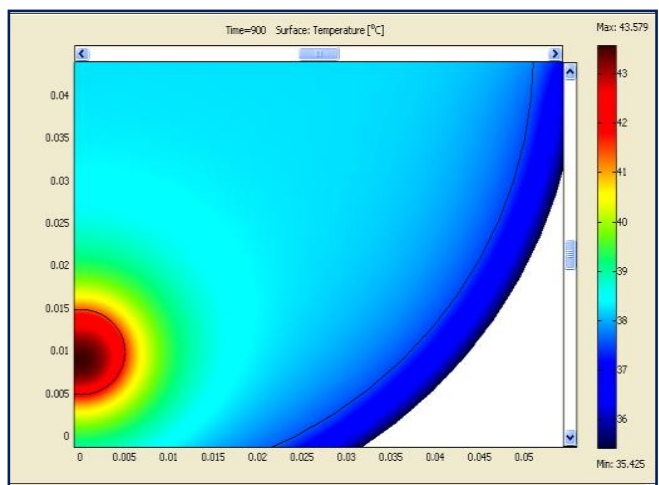

Fig. 6 the effect of laser power density (a) $8000 \mathrm{~W} / \mathrm{m}^{2}$ (b) $10500 \mathrm{~W} / \mathrm{m}^{2}$ (c) $13000 \mathrm{~W} / \mathrm{m}^{2}$ (d) $15500 \mathrm{~W} / \mathrm{m}^{2}$ (e) $18000 \mathrm{~W} / \mathrm{m}^{2}$. 
Also, for intensities below $13000 \mathrm{~W} / \mathrm{m}^{2}$, the average temperature of the tumor begin to gradually decline after about 650-800s as shown in Figure (7), which demonstrates the effect of using different, laser intensities on the tumor over the same period of treatment. So laser intensity of $13000 \mathrm{~W} / \mathrm{m}^{2}$ or higher would be ideal. Moreover, the study of hyperthermia treatment of breast tumors shows that a target temperature of around $42-43^{\circ} \mathrm{C}$ is suitable for treatment [12]. According to this, our model results suggest that a laser intensity of 18000 $\mathrm{W} / \mathrm{m}^{2}$ would be optimal.

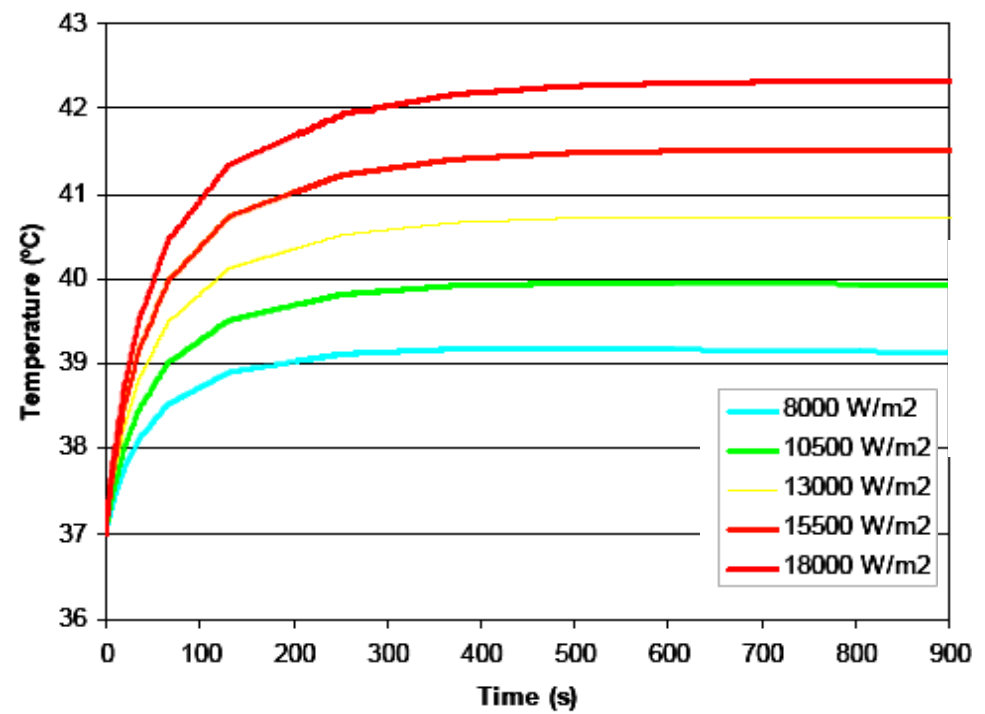

Fig. 7 Average tumor temperature over time during irradiation with laser of various intense.

\subsection{Effect of Laser on Different Sizes of Breast Tumors:}

We have investigated the effect of the laser on different sizes of breast tumors as a case study, to examine the sensitivity of our model on different sizes of breast tumors and determine the best size to be use in hyperthermia treatment of breast tumors. We changed the breast tumors diameters to be $5 \mathrm{~mm}, 10 \mathrm{~mm}, 20 \mathrm{~mm}$ and $30 \mathrm{~mm}$, at the same laser intensity of $13000 \mathrm{~W} / \mathrm{m}^{2}$ and same exposure interval of time (900s).

We noticed that as the size of breast tumors increases, the temperature increases at the same conditions as shown in Figures $(8,9)$, we find the $5 \mathrm{~mm}$ tumors reached to $40{ }^{\circ} \mathrm{C}$ although the biggest size $30 \mathrm{~mm}$ reached to $46^{\circ} \mathrm{C}$. From the results our model suggests that the best size that suite the hyperthermia treatment can be achieved in the case of breast cancer size of around $10 \mathrm{~mm}$ in diameter.

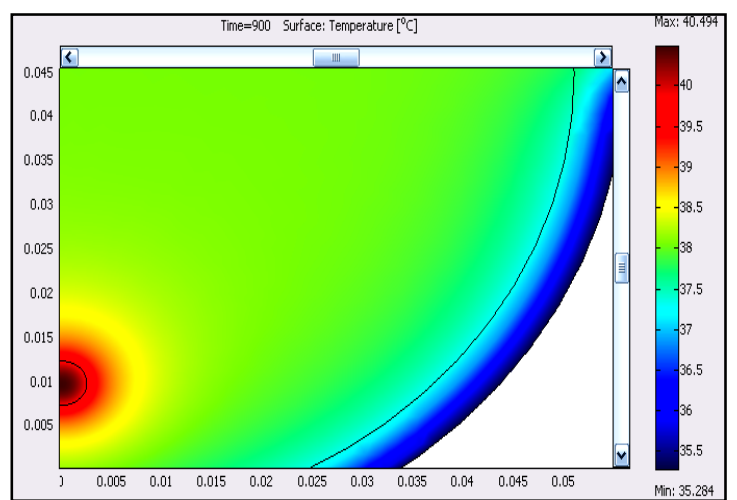

(a)

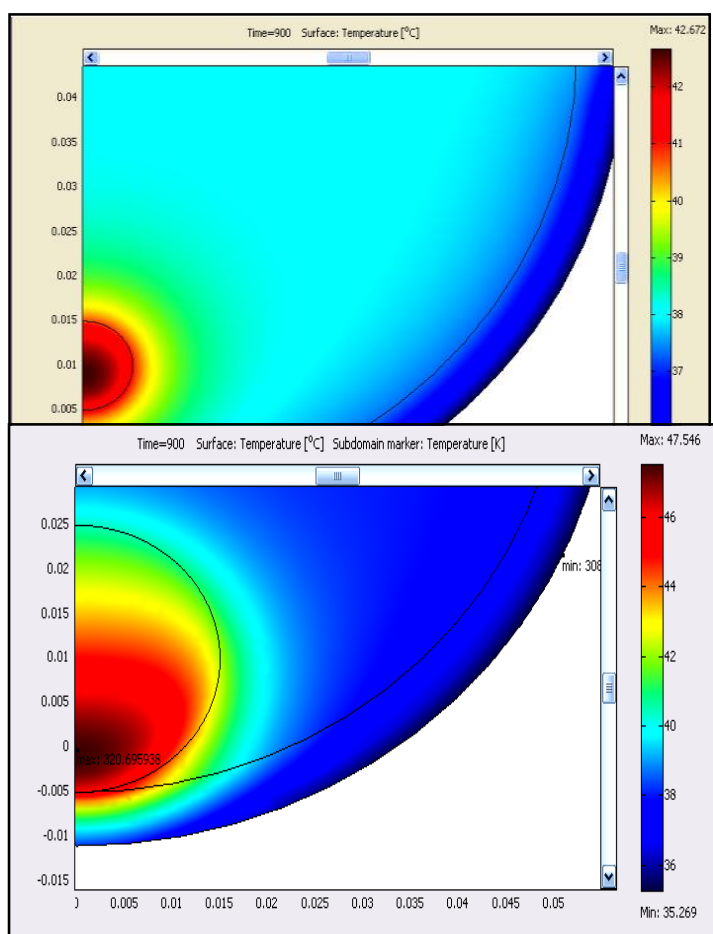




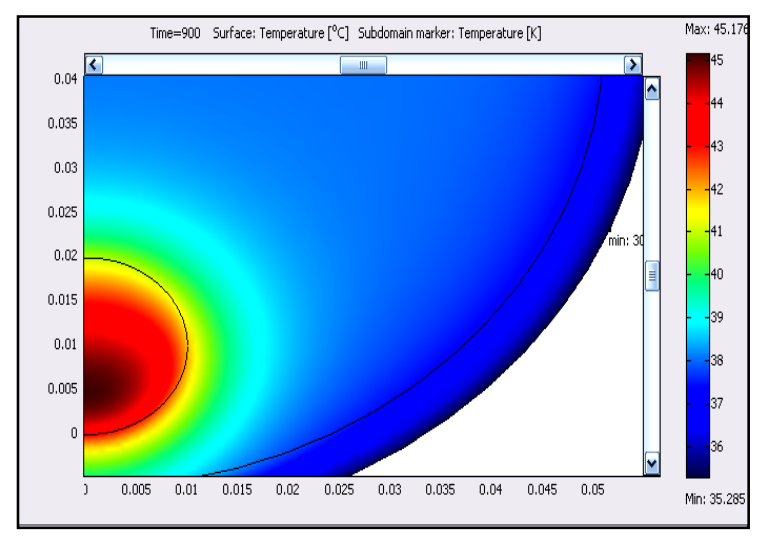

(c) (d)

Fig .8 The effect of the same laser intensity on different sizes of tumors (a) $5 \mathrm{~mm}$, (b) $10 \mathrm{~mm}$, (c) $20 \mathrm{~mm}$, (d) $30 \mathrm{~mm}$ in diameters.

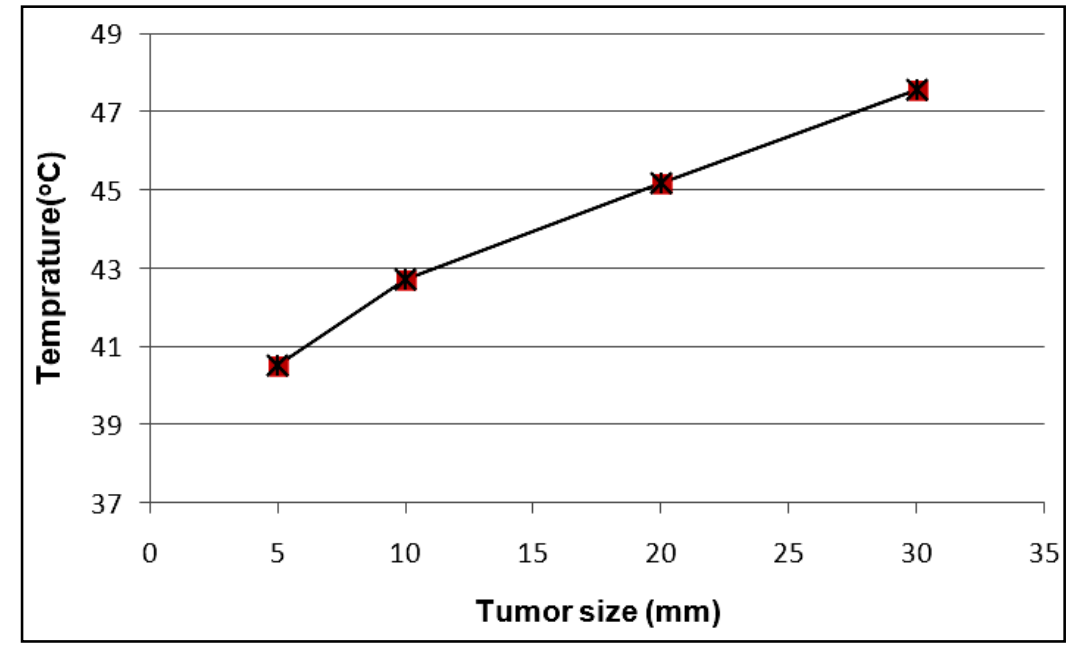

Fig. 9 Show that the temperature increases as the tumor size increase for the same time interval of laser irradiation.

\section{7- Conclusions and Discussions:}

Experimental evidence shows that laser treatment for an hour at around $42.5^{\circ} \mathrm{C}$ is ideal for hyperthermia treatment [12]. Based on our sensitivity analysis, we recommend that a laser intensity of $18000 \mathrm{~W} / \mathrm{m}^{2}$ be employed for hyperthermia treatment of breast tumors for the purpose of increasing tumor cell radio sensitivity [7]. This intensity was deemed ideal for two reasons: (1) it resulted in a near-steady-state average tumor temperature after a brief initial period of about 600s and (2) it increase the average tumor temperature to about $42.5^{\circ} \mathrm{C}$, which is squarely in the range of ideal temperature for hyperthermia treatment [12].

Moreover, we recommend that a cooling air boundary condition be used. Our model suggests that flowing $10^{\circ} \mathrm{C}$ water over the surface of the breast results in a net cooling (rather than heating) of the tumor, which clearly is undesirable. In contrast, an ambient air boundary condition at the breast surface gave an ideal curve for the average tumor temperature over time. That is, one in which a constant temperature is reached quickly and sustained over time. Hence, for this reason and because it was more closely matches the reality (that is, it would be unrealistic to maintain a flow of water with such high convective heat transfer coefficient over the breast surface during laser treatment), we chose to use the air boundary condition throughout our study. 
We have also studied the effect of the laser on different sizes of breast tumors and we noticed that as the size of breast tumors increases, the temperature increases at the same conditions of laser intensity and irradiated time interval. Our model suggests that the best size that suite the hyperthermia treatment is around $10 \mathrm{~mm}$ in diameter.

Hyperthermia treatment is attractive because it increases the sensitivity of tumor cells to radiation and thus increases its efficacy. In doing so, it improves this widely-used noninvasive treatment for malignant tumors [7], and hyperthermia treatment helps to eliminate some of the danger of radiation therapy by potentially reducing the amount of radiation employed in each treatment and the number or frequency of treatments. In a similar manner, hyperthermia treatment can reduce costs to both health care providers and patients by avoiding operations and reducing the number of radiation treatments [7].

\section{References:}

[1] Mueller G, Roggan A, "Laser-Induced Interstitial Thermotherapy", SPIE-The International Society for Optical Engineering, 1995.

[2] Intraocular Nd:YAG Laser Surgery, "Light-Tissue Interaction, Damage Range, and Reduction of Collateral Effects", IEEE JOURNAL OF QUANTUM ELECTRONICS, VOL 26, NO 12, DECEMBER 1990.

[3] "Minimally Invasive Ablation Techniques in Breast Cancer Treatment", Published by Lippincott Williams \& Wilkins, the Society of Surgical Oncology, Inc., 2002

[4] Yassene.M , and Janko F Verhey "A finite element method model to simulate laser interstitial thermo therapy in anatomical inhomogeneous regions", BioMedical Engineering OnLine, 2005.

[5] "Breast Cancer in Men: Cancer Research UK", Cancer Research UK, Retrieved on 2007$\underline{1106}, 2007$.

[6] "All About Breast Cancer", American Cancer Society, Accessed 24 April 2007. $<$ http://www.cancer.org/docroot/CRI/CRI_2x.asp?sitearea=\&dt=5>.

[7] "HYPERTHERMIA, SYSTEMIC" Encyclopedia of Medical Devices and Instrumentation, Second Edition, edited by John G. Webster, 42-62, 2006.

[8] He Y, Shirazaki M, Lui H, Himeno R, Sun Z, "A numerical coupling model to analyze the blood flow, temperature, and oxygen transport in human breast and tumor under laser irradiation", Computers in Biology and Medicine, 36, 1336-1350, 2006.

[9] Ashley J, Welch M, van Gemert JC, "Optical-Thermal Response of Laser-Irradiated Tissue", 1st edition, New York, Plenum Press, 1995.

[10] A. Bejan, "Heat Transfer", Wiley, 1993.

[11] Ng. EYK. and Sudharsan NM., "An improved three-dimensional direct numerical modeling and thermal analysis of a female breast with tumor", Proceedings Institution of Mechanical Engineers, 215, 2001.

[12] Zhu D, Lu W, Weng Y, Cui H, Luo Q, "Monitoring thermal-induced changes in tumor blood flow and microvessels with laser speckle contrast imaging", Applied Optics, 46(10), 1911-1917, 2007. 